\title{
IES
}

\section{EDUCATIONAL REFORM, ABILITY AND FAMILY BACKGROUND}

Costas Meghir Mårten Palme 


\title{
Educational Reform, ability and family background*
}

\author{
Costas Meghir ${ }^{\dagger}$ and Marten Palme
}

April 26, 2004

\begin{abstract}
In this paper we evaluate the impact of a major school reform, that took place in the 1950s in Sweden, on educational attainment and earnings. The reform, which has many common elements with reforms in other European countries including the UK, consisted of increasing compulsory schooling, imposing a national curriculum and abolishing selection by ability into Academic and non-academic streams at the age of 12 (comprehensive school reform). Our data combines Survey data with administrative sources. We find that the reform increased both the educational attainment and the earnings of children whose fathers had just compulsory education. However the earnings of those with educated parents declined - possibly beacause of a dilution of quality at the top end of the education levels. The overall effect of the reform was however positive.
\end{abstract}

JEL: H52, I21, I28, J24, J31.

Keywords: Human Capital, Evaluation of Education Reform, Comprehensive Schools, Compulsory Schooling, Earnings, Adminstrative Data, Difference in Differences.

*We thank two anonymous referees the co-editor David Card, Jerome Adda, Josh Angrist, Orazio Attanasio, Anders Björklund, Richard Blundell, Lorraine Dearden, Christian Dustmann, Jim Heckman, Guido Imbens, Mac Murray, Jan O. Jonsson, Lars-Erik Öller, Emma Rothschild, Barbara Sianesi, Chris Taber, Frank Vella, Ed Vytlacil as well as participants in the conference on evaluation of education policies at the Hebrew University and in seminars at the Universities of Bergen, Chicago, Columbia, Princeton, Umeå, and Uppsala, the Tinbergen Institute in Amsterdam, the Trade Unions Institute for Economic Research in Stockholm and IIES at Stockholm University for comments and suggestions; Finally, we would like to thank the Department of Education, University of Gothenburg for letting us use their data. Marten Palme acknowledges financial support from the Swedish Council for Social Research. Costas Meghir acknowledges financial support from the ESRC via the CFP at the IFS and from the Centre for the Economics of Education funded by the DfEE. The usual disclaimer applies.

$\dagger$ Institute for Fiscal Studies and Department of Economics, University College London, Gower Street, London WC1E 6BT, UK. E-mail: C.Meghir@ucl.ac.uk.

${ }^{\ddagger}$ Department of Economics, Stockholm University, SE-106 91 Stockholm, Sweden. E-mail: Marten.Palme@ne.su.se. 


\section{Introduction}

In the period between 1950 and mid 1970s many European countries carried out major educational reforms that resulted in increases in the compulsory years of education, in the introduction of nationally unified curricula and in the abolition, or delay, of the selection of more able students into separate schools at an early age (streaming). Examples of such countries are the UK, France and the Scandinavian countries. ${ }^{1}$ Generally, it is very difficult to evaluate the impact of such reforms because they are implemented nationally at once and thus evaluations have to rely on before and after comparisons which may confound the effects of the policy with other macro-aggregate or cohort effects. ${ }^{2}$

In Sweden a major educational reform was designed in the late 1940s. The main elements of this reform were to a) increase compulsory schooling to 9 years from 7 or 8 ; b) to abolish selection based on grades into an academic and nonacademic stream after grade 6, i.e. age 12 or 13; and c) to impose a nationally unified curriculum. From an evaluation point of view, an attractive feature of this reform is that it was preceded by a social experiment, albeit not randomized, where the new school system was implemented gradually across municipalities. This allows for an evaluation approach similar to those that have been used in a number of US studies, which have exploited the cross state and cross time variation in compulsory schooling laws and child labour laws to estimate their impact on educational attainment or to estimate the returns to education. ${ }^{3}$

In this study we evaluate the effect of the reform on final educational attainment and earnings. We have survey data on two cohorts of pupils: those born in 1948 and in 1953, respectively. For a substantial proportion of the municipalities, these two cohorts were assigned to different school systems: the 1948 cohort to the old system and the 1953 cohort to the new one. However in other municipalities both cohorts

\footnotetext{
${ }^{1}$ See e.g. Leschinsky and Mayer (1990) for an overview.

${ }^{2}$ See Harmon and Walker (1995).

${ }^{3}$ For the former, see e.g. Margo and Finegan (1996) and for the latter, Angrist and Krueger (1991), the survey in Card (1999, 2001) and Acemoglu and Angrist (2000).
} 
were assigned to the old system, while in others both cohorts were assigned to the new reformed system. This allows us to evaluate the reform using a differences-indifferences methodology, comparing outcomes across cohorts and municipalities. The data for the two cohorts contain information on parental background, scores from IQ tests and information on achievement in school (subject grades) in grade 6. Educational attainment and earnings are merged in to the original survey data from the national education register and the 1985-96 tax records respectively.

The distinctive feature of this policy experiment, combined with the data, is that we can compare individuals working in the same labor market at the same point in time, who have attended two different school systems. In addition we are able to look at heterogeneous impacts by parental background and ability. In particular, low education of the parents tends to be associated with low educational outcomes of the children, ${ }^{4}$ possibly because of liquidity or informational constraints or lower investments early in life. Our data allows us to estimate the extent to which the reform benefited those with unskilled parents and to see the extent to which such effects differ by ability. Thus our analysis relates directly to key issues of policy as expressed in Heckman (2000), Krueger (2002) and Carneiro and Heckman (2003).

\section{The 1950 Education Reform and the Social Experiment}

In the pre-reform school system pupils first attended a common a Basic compulsory school (folkskolan) up until the 6th grade. Starting in 7 th grade students with better school achievement (measured by subject grades) were selected for the Junior secondary school. Those who were not admitted continued one or two years in Basic compulsory school and thereafter could continue in full time vocational education. ${ }^{5}$ Overall compulsory schooling lasted seven years and in some munici-

\footnotetext{
${ }^{4}$ See for example Dearden, Ferri and Meghir (2002) among others.

${ }^{5}$ There was also a second chance of entering Junior secondary school after completing basic compulsory education. However pupils admitted to Junior Secondary at this later point would have to begin from the start of Junior Secondary leading to a one or two year delay relative to the others of the same cohort who were admitted in the first round.
} 
palities, mainly in city communities, eight years. The Junior secondary school was a prerequisite for the upper secondary school, which, in turn, was a prerequisite for higher education.

In 1948, a parliamentary committee proposed to replace the old compulsory and selective junior secondary school with a nine year compulsory comprehensive school. The students would be able to choose between three different routes after sixth grade: one with a more academic curriculum, one general level and one level which included vocational training. However, there would be no selection based on grades and all pupils would attend the same schools under the new system. Finally, all schools would have the same national curriculum. ${ }^{6}$

The proposals led to a nationwide evaluation experiment between 1949 and 1962, when it was decided to implement the new school system nationally. ${ }^{7}$ In the experiment, the proposed comprehensive school was introduced by areas, i.e. entire municipalities or parts of city communities, rather than by separate schools or classes. By the time the experiment started, Sweden was divided into about 2,500 city communities and rural municipalities. The number of municipalities was, however, reduced to 1,037 in a reform of the municipality system in 1952, which is the municipality division that we use in the empirical analysis.

The municipalities that would implement the new system were not chosen randomly; the National School Board, which administered the experiment, chose them out of a group of applicants, so as to form a representative set in the board's judgement, based on municipality characteristics. The final decision on reform assignment was made by the municipality council. A means tested stipend was also introduced in 1953 in the reform areas to ease the perceived financial burden of extending the years of schooling .

New municipalities were added every year to the reform. In 1961, at the time

\footnotetext{
${ }^{6}$ The reform is described in e.g. Marklund (1981) and Paulston (1968). Marklund also offers a description of the social experiment preceding it.

${ }^{7}$ The official evaluation (Försöksverksamhet med nioårig skolplikt, 1959) described in Marklund (1981) was mainly of an administrative nature. No educational or labour market outcomes have been considered before.
} 
when the data for the first cohort were collected (born in 1948) about 25 percent of the municipalities were assigned to the reform. Although national implementation of the reform took place in 1962, the cohort from which the new school system was implemented varied between municipalities; some municipalities implemented the new system starting from the cohort of pupils who were in 1st grade in 1962 while others implemented it for older cohorts as well up to those which were attending 5th grade in 1962. This implies that in 1966, when the data for the second cohort (born in 1953) were obtained, about 30 percent of the municipalities maintained the pre reform school system for those born in 1953. Thus, for both the 1948 and the 1953 cohorts there are both treatment (reform) and comparison (old system) municipalities. Crucially there is a large proportion of municipalities for which the 1948 cohort attended the old system and the 1953 cohort attended the new reformed one. Once a cohort started in the old system it was not switched over subsequently.

\section{Data: Measurement and Sample Selection}

We use data from the 1948 and 1953 cohorts of the Individual Statistics (IS) project of the Institute for Education at the University of Gothenburg. ${ }^{8}$ The 1948 and 1953 cohort surveys were obtained in the spring of 1961 and 1966 respectively, when the respondents were in the 6th grade of compulsory school. The same sampling strategy was used for both surveys, namely that all children born the 5th, 15th or 25 th in each month were selected to be included in the sample. With a rate of non-response for the 1948 cohort survey of about 1.8 percent and 7.4 percent for the 1953 cohort, the final sample size was 11,950 and 9,927 respectively or about 10 percent of the entire cohorts.

The original data-set includes information for each student on the education of her/his parents; results from three different IQ tests (number series, opposites and folding); administrative information on grades (Swedish, English and Mathe-

\footnotetext{
${ }^{8}$ See Härnqvist and Svensson (1973) for a detailed description of the project and the data.
} 
matics) and type of school. Thus all measures of student ability were obtained in 6th grade. We use all the test scores to construct ability indicators included in the empirical analysis. Information on final educational attainment was obtained from the 1990 Swedish education register. ${ }^{9}$ Finally, information on annual earnings and employment status for each year from 1985 to 1996 was obtained from the Swedish tax registers. ${ }^{10}$

Sweden is divided administratively into 24 counties, each of which contains a number of municipalities within commuting distance of each other. The counties are often used to define local labor markets (see e.g. Westerlund, 1997). Importantly, all counties but one for the 1948 cohort and all counties for the 1953 cohort had some reform and some non-reform municipalities or parts of city communities. The final sample size was 10,638 (5,387 men and 5,251 women) and 9,105 (4,578 men and 5,527 women) for the 1948 and 1953 cohort surveys respectively. For each we observe earnings for the entire (or part of) the 1985 to 1996 period.

\section{Estimating the Impact of the Reform on Educational Qual- ifications and Earnings}

To evaluate the impact of the reform we consider years of education, the level of education as measured by two binary outcomes (whether the final completed level of education was the new compulsory level or any other and whether the completed level of education was more than the new compulsory level or any other) and log annual earnings over the years 1985-1996.

The reform was assigned to entire municipalities or communities within the large cities. For the 1948 cohort, 34\% of pupils were assigned to the reformed system over the whole country, based on where they lived when they were in grade 6. The remaining pupils were assigned to the old system. In the case of the 1953 cohort, $81 \%$ were assigned to the reformed system.

\footnotetext{
${ }^{9}$ We also summarise overall educational attainment using years of education. Since this is not observed directly we impute it by assigning years of education based on the Swedish Level of Living Survey to each of seven educational levels that we observe in the data.

${ }^{10}$ Details of the data can be found in Meghir and Palme (2003).
} 
The sample can thus be split up in the following groups: a) municipalities or city communities in which the 1948 cohort was not assigned to the reform but the 1953 cohort was - these are the switching municipalities; b) municipalities in which both the 1948 and the 1953 cohorts were assigned to the reform; c) municipalities in which neither the 1948 nor the 1953 cohorts were assigned to the reform.

The assumption we make is that, conditional on the individual observed characteristics, the change in average outcomes ${ }^{11}$ between the 1948 and 1953 cohorts for individuals living in the municipalities that switched into the reform (group (a) above) would have been the same in the absence of the switch as the change for individuals living in the municipalities that did not change reform status. We also assume that municipalities did not change teaching methods or otherwise take preemptive action before they were assigned to the reformed system. Under these identifying assumptions we can evaluate the impact of the reform using differencesin-differences (Ashenfelter, 1978, Heckman and Robb, 1985); that is we compare the change in average outcomes between the 1948 and 1953 cohorts for individuals living in the switching municipalities when in grade 6 to the change in average outcomes for the same cohorts of individuals living in the municipalities that did not change reform status. As a robustness check we also estimate the impacts separately using as comparison groups either individuals living in municipalities that implemented the reform for both cohorts (group (b)) or individuals living in municipalities that kept the old system for both cohorts (group (c)).

The linear regression that implements the differences-in-differences estimator is

$$
Y_{i d m}=b_{0}+b_{1} d_{i}+b_{2}^{\prime} m_{i}+\alpha r_{i d m}+\gamma^{\prime} x_{i d m}+e_{i d m},
$$

where $Y_{i d m}$ is the relevant outcome observed for individual $i$ belonging to cohort $d$ and municipality $m, d_{i}$ is a dummy variable indicating the cohort to which the individual belongs to and $m_{i}$ is a set of dummy variables indicating the municipality in which individual $i$ went to school; ${ }^{12} r_{i d m}$ is 1 for individuals belonging

\footnotetext{
${ }^{11}$ Educational attainment and earnings.

${ }^{12}$ For pupils educated in Stockholm, Gothenburg and Malmo we are not able to include fixed
} 
to a cohort and municipality assigned to the reformed system. The parameter $\alpha$ is the average effect of the reform for those assigned to it amongst the population from which the sample is drawn. ${ }^{13}$ The variables $x_{i d m}$ reflect the observable characteristics of individual students. Finally $e_{i d m}$ represents a random error term assumed uncorrelated with $r_{i d m}$ conditional on the other regressors, i.e. we assume that $E\left(e_{i d m} \mid r_{i d m}, d_{i}, m_{i}, x_{i d m}\right)=E\left(e_{i d m} \mid d_{i}, m_{i}, x_{i d m}\right)$. The additive municipality $(m)$ and cohort effects $(d)$ in (4.1) together with the stated properties of the error term reflect the assumptions underlying the differences-in-differences approach, as stated above.

For log earnings and years of education we use Ordinary Least Squares (OLS) on (4.1). For the discrete educational outcomes we use a probit model. This requires the additional assumption that $e_{i d m}$ is normal conditional on $r_{i d m}, d_{i}, m_{i}, x_{i d m}$. However, a linear probability model gave almost identical results. In all cases the covariates $x$ include indicators for test scores and school grades obtained when the pupils were in grade 6 and the county of work. ${ }^{14}$ When we present results pooled across males and females we include a gender dummy on its own and interacted with all $x$ 's. Since for each individual we have repeated earnings observations over the period 1985-96, we also include time dummies for these years in the earnings regressions. Thus we effectively compare the earnings of individuals within the same local labour market and year.

In computing the standard errors of the estimates we allow for the possibility that the errors $e_{i d m}$ are correlated across individuals within a municipality of schooling. This also allows for arbitrary serial correlation. ${ }^{15}$

Appendix Table 1 presents descriptive statistics and reports the difference in some characteristics between individuals living in switching and non-switching mueffects for the particular community in which they live in. However we include dummies for each of these cities.

${ }^{13}$ So for example when we estimate using the pooled sample of males and females with unskilled fathers, the effect is the average effect over that population.

${ }^{14}$ The test scores include three IQ tests as shown in the Appendix Table and school grades in Swedish, English, Mathematics.

${ }^{15}$ See Moulton (1986) for the importance of controlling for cluster effects. 
nicipalities. These differences are not significant, implying there would be no bias if we excluded these covariates from the regression. However we still include the covariates so as to improve estimated precision, because they are highly correlated with both educational attainment and earnings.

A reform of this magnitude may have had aggregate effects on the labour market including on the price of labour. However, since we compare workers with the same labour markets our estimates do not include such effects. ${ }^{16}$ They reflect the relative merits of the two school systems given the overall macroeconomic conditions.

\section{Results}

\subsection{The Effect of the Reform on Education}

The estimates of the impact of the reform on education are shown in Table 1. These are presented for the whole sample and by gender. We also break them down by father's education (low and high) ${ }^{17}$ and by ability (low and high). ${ }^{18}$ We refer to fathers with low education as unskilled fathers. For years of education we report the OLS estimate of $\alpha$ from equation 4.1 which represents the effect of the reform measured in years of education. For the educational levels the estimates are the marginal effects of the reform from a probit model, based on 4.1, multiplied by 100 to transform them to percentage point effects on the probability of attending the level in question.

The average effect of the reform for men and women was to increase the proportion attending up to the new compulsory level by 8.6 percentage points and beyond that level by 2.6 percentage points, showing that the reform had an impact beyond the new compulsory level; this is consistent with the aim of the reform to improve access to higher levels of education.

\footnotetext{
${ }^{16}$ See Lang and Kropp (1986).

${ }^{17}$ Unskilled fathers are defined as those with just compulsory education or education missing. The constitute approximately $83 \%$ of the sample reflecting the low educational attainment of individuals born in the 1920s and 1930s.

${ }^{18}$ To define the ability groups we take the average IQ score across three different IQ tests for each person and classify individuals with score above the sample median as high ability.
} 
All changes in educational attainment taken together translate into an increase in years of education by 0.298 of a year. All these effects are highly significant. The entire effect is due to the increase in the educational attainment of those with unskilled fathers (column 2). Within that group, those with low ability increased their attainment by moving up to the new compulsory level with an almost equal drop in the proportion attending the old compulsory one. However for those of higher ability the increase in attainment is reinforced by a large increase beyond the new compulsory level (column 4). Thus it seems that the measures for improving access beyond the new compulsory level had an important impact for the more able with unskilled fathers.

The Table also breaks down the effect by men and women. The main difference revealed here is that the increase beyond the new compulsory level is stronger for women.

\subsection{The Effect of the Reform on Earnings}

We estimate the impact of the reform on average annual log-pre-tax earnings for both men and women, with positive earnings over all or part of the years in the 1985-96 time period for which earnings are observed. ${ }^{19}$ We report the OLS estimate of $\alpha$ from equation 4.1 multiplied by 100, so that the reported effects can be interpreted as the percent effects on earnings averaged over the observation period. The results are shown in Table 2.

The overall effect of the reform on earnings at $1.45 \%$ was small and only significant at the $8.8 \%$ level. However, this hides important heterogeneity in the effects for different groups of individuals. For those with unskilled fathers the reform increased earnings by $3.4 \%$ which is highly significant. In terms of the point estimates the effect is larger for the high ability individuals but the difference is not significant. One of the striking results (which explains the small overall effect) is the negative impact $(-5.5 \%)$ on the earnings of individuals with skilled parents

\footnotetext{
${ }^{19}$ There was no effect of the reform on the proportion of individuals with positive earnings.
} 


\begin{tabular}{|c|c|c|c|c|c|}
\hline & $(1)$ & $(2)$ & (3) & $(4)$ & $(5)$ \\
\hline Father's education $^{a}$ & All & Low & Low & Low & High \\
\hline Ability $^{b}$ & All & All & Low & High & All \\
\hline \multicolumn{6}{|c|}{ Men and Women } \\
\hline \multicolumn{6}{|l|}{ Change in percent attending: ${ }^{c}$} \\
\hline Comprehensive/ & 8.57 & 10.34 & 16.82 & 2.26 & 2.14 \\
\hline Junior Secondary & $(1.68)$ & $(2.14)$ & $(2.73)$ & $(2.73)$ & $(1.26)$ \\
\hline More than Comprehensive/ & 2.63 & 3.28 & 1.41 & 6.19 & -1.16 \\
\hline Junior Secondary & $(1.14)$ & $(1.42)$ & $(1.96)$ & $(2.33)$ & $(1.46)$ \\
\hline \multirow[t]{2}{*}{ Change in years of education: } & 0.298 & 0.406 & 0.427 & 0.358 & -0.132 \\
\hline & $(0.075)$ & $(0.070)$ & $(0.101)$ & $(0.101)$ & $(0.123)$ \\
\hline Years of education & 11.18 & 10.77 & 10.01 & 11.91 & 13.68 \\
\hline in non-reform areas & $(0.032)$ & $(0.033)$ & $(0.036)$ & $(0.055)$ & $(0.085)$ \\
\hline Sample Size & 19,550 & 16,227 & 8,760 & 7,467 & 3,323 \\
\hline \multicolumn{6}{|c|}{ Men } \\
\hline \multicolumn{6}{|l|}{ Change in percent attending: ${ }^{c}$} \\
\hline Comprehensive/ & 9.90 & 12.29 & 17.82 & 4.74 & 2.12 \\
\hline Junior Secondary & $(2.37)$ & $(2.97)$ & $(3.87)$ & $(3.75)$ & $(1.56)$ \\
\hline More than Comprehensive/ & 0.79 & 1.17 & -0.47 & 5.30 & -1.48 \\
\hline Junior Secondary & $(2.17)$ & $(2.63)$ & $(3.36)$ & $(3.74)$ & $(1.67)$ \\
\hline \multirow[t]{2}{*}{ Change in years of Education } & 0.254 & 0.304 & 0.407 & 0.101 & 0.095 \\
\hline & $(0.081)$ & $(0.093)$ & $(0.105)$ & $(0.164)$ & $(0.173)$ \\
\hline Sample Size & 9,861 & 8,187 & 4,704 & 3,483 & 1,674 \\
\hline \multicolumn{6}{|c|}{ Women } \\
\hline \multicolumn{6}{|l|}{ Change in percent attending: ${ }^{c}$} \\
\hline Comprehensive/ & 7.52 & 9.06 & 16.68 & -1.09 & 3.33 \\
\hline Junior Secondary & $(1.86)$ & $(2.49)$ & $(3.03)$ & $(4.69)$ & $(2.49)$ \\
\hline More than Comprehensive/ & 4.63 & 5.40 & 3.58 & 8.65 & -2.17 \\
\hline Junior Secondary & $(1.85)$ & $(2.15)$ & $(3.04)$ & $(4.27)$ & $(2.61)$ \\
\hline \multirow[t]{2}{*}{ Change in years of Education } & 0.339 & 0.512 & 0.438 & 0.592 & -0.404 \\
\hline & $(0.104)$ & $(0.087)$ & $(0.141)$ & $(0.134)$ & $(0.192)$ \\
\hline Sample Size & 9,689 & 8,040 & 4,056 & 3,984 & 1,649 \\
\hline
\end{tabular}

Notes: Asymptotic Standard errors in parentheses allowing for clustering by municipality. ${ }^{a}$ Low Father's education: The father had just compulsory schooling of his time ${ }^{b}$ High ability: Individual IQ score above median. ${ }^{c}$ This is measured in percentage points.

Table 1: The impact of the reform on educational attainment 
who constitute $17 \%$ of the population. This is true for both males and females and despite the fact that there is no significant change in educational attainment for the group. These individuals used to attend primarily the academic Junior secondary school which selected on the basis of attainment in grade 6 . The reform abolished this selection and it seems that this reduced the quality of education and ultimately the earnings of this group.

Finally, since both the amount of education and the quality/type of education changed for individuals of all abilities among those with unskilled fathers, it is not possible to say which aspect of the reform led to the earnings gains. If all the earnings changes were due to changes in the quantity of education, this would correspond to a return to education of $7.3 \%$ for the low ability individuals and $12.3 \%$ for the high ability ones (8.5\% overall); if one accepts that the other changes enhanced earnings for this group by improving the quality of education these will be upper bounds to the effects of education on earnings.

When we break down the effects by gender we note that the effects for individuals with unskilled fathers are higher for women than men but both significant. For men we cannot distinguish much of a difference between those of high and low ability; however for high ability women the effect is larger than for lower ability women, but not significantly so since the p-value for the difference of the two effects is $18.7 \%$.

\subsubsection{Sensitivity Analysis}

In Table 3 we present the results of some sensitivity analysis to demonstrate the robustness of the results. For the sake of brevity we only present the average effects across males and females split by father's education which seems to be the most important source of heterogeneity for the impacts on earnings.

We re-estimated the model using first as controls individuals living in municipalities that implemented the reform for both cohorts (column 1, Table 3) and then using as controls individuals living in municipalities that kept the old system 


\begin{tabular}{lccc}
\hline \hline & \multicolumn{3}{c}{ Differences-in-differences } \\
& Males and Females & Males & Females \\
& & & \\
\hline All & $(0.45$ & 0.91 & 2.14 \\
& & $(1.36)$ & $(1.23)$ \\
Low father's education & 3.39 & 3.09 & 3.80 \\
All abilities pooled & $(0.90)$ & $(1.36)$ & $(1.29)$ \\
& & & \\
Low father's education & 2.81 & 2.90 & 2.72 \\
Low ability & $(1.25)$ & $(2.00)$ & $(1.60)$ \\
& & & \\
Low father's education & 4.14 & 3.03 & 5.86 \\
High ability & $(1.25)$ & $(1.90)$ & $(2.03)$ \\
& & & \\
High father's education & -5.54 & -7.53 & -3.95 \\
All abilities pooled & $(1.87)$ & $(3.12)$ & $(2.70)$ \\
& & & \\
& & & \\
\hline
\end{tabular}

Note: Standard errors in round brackets allowing for clustering by municipality thus also allowing for arbitrary serial correlation.

Coefficients are interpreted as percentage effects on annual earnings.

Table 2: The impact of the reform on earnings.

\begin{tabular}{|c|c|c|c|c|c|}
\hline & $(1)$ & $(2)$ & $(3)$ & $(4)$ & $(5)$ \\
\hline & \multicolumn{5}{|c|}{ Males and Females $^{a}$} \\
\hline & \multicolumn{2}{|c|}{ Alternative Comparison Groups } & \multirow{2}{*}{$\begin{array}{l}\text { Excluding Stockholm, } \\
\text { Gothenburg \& Malmo }\end{array}$} & \multicolumn{2}{|c|}{ Impact of mobility } \\
\hline & $\begin{array}{l}\text { Reform for } \\
\text { both cohorts }\end{array}$ & $\begin{array}{l}\text { Non-Reform for } \\
\text { both cohorts }\end{array}$ & & $\begin{array}{l}\text { Excluding } \\
\text { movers }^{b}\end{array}$ & $\mathrm{IV}^{c}$ \\
\hline Low Father's Education & 3.12 & 2.94 & 3.89 & 4.14 & 3.93 \\
\hline All abilities pooled & $(0.93)$ & $(0.92)$ & $(1.19)$ & $(1.01)$ & $(2.69)$ \\
\hline High Father's Education & -5.88 & -5.70 & -5.98 & -3.15 & -19.55 \\
\hline All abilities pooled & $(1.89)$ & $(2.05)$ & $(3.43)$ & $(2.70)$ & $(13.03)$ \\
\hline
\end{tabular}

Notes: ${ }^{a}$ Asymptotic standard errors allowing for clustering by municipality in parentheses. ${ }^{b}$ We exclude those who as a result of a move changed reform status from that implied by the municipality of birth.

${ }^{c}$ In IV we instrument actual reform status using the status predicted by the municipality of birth.

Table 3: Results from sensitivity analysis on the impact of the reform on earnings. 
for both cohorts. As can be seen from the Table, the results are remarkably similar to those presented in Table 2 which uses both comparison groups.

In column 3 we show results from excluding the three big cities of Stockholm, Gothenburg and Malmo mainly to check whether the effects are substantially different in the rest of the country which is under-represented in the reform. Again the effects are very similar to those reported in Table 2.

Finally we estimated the effects using propensity score matching based on the 1948 cohort only. These estimates do not control for unobserved municipality characteristics but do not rely on additive (in logs) cohort effects since we compare only within cohort. The results, reported in detail in Meghir and Palme (2003), are less precise but display very similar patterns.

\subsubsection{Selective Mobility and the Impact of the Reform}

Families may have moved municipality so as to choose the suitable schooling for their children. We use the municipality of birth to assess the extent to which this may have affected the results we report. For some individuals it is not possible to know whether they would have been in the reform or not on the basis of their place of birth mainly because the municipality borders were adjusted after the birth of our cohorts. Overall we were able to classify $87.3 \%$ of the sample. Of these $90.1 \%$ did not change reform status from that implied by where they were born. Of the 9.9\% who we know changed status $5.3 \%$ moved from a reform to a non-reform municipality and $4.6 \%$ went the other way. Details on this for the 1948 cohort are given in Meghir and Palme (2003).

We can use the birth municipality in two ways. First we re-estimate the model only on those who did not change status as a result of moving out of the municipality of their birth. The results are shown in column 4 of Table 3 and they are not significantly different to those in Table 2. Based on a Hausman test, ${ }^{20}$ for those with unskilled fathers the difference has a t-value of 1.63. For those with

\footnotetext{
${ }^{20}$ The rationale for carrying out a Hausman test is that the estimation based on the non-movers is inefficient under the null relative to keeping the whole sample.
} 
higher father's education we still get a negative effect but smaller in absolute value. The t-statistic for the difference from the estimate in Table 2 is 1.23 which is not significant at the $5 \%$ level.

We also re-estimated the model using Instrumental variables, treating reform allocation as endogenous even conditional on the observables and the municipality fixed effects. The instruments are a) whether we know the reform status or not based on the birth municipality and b) if we know whether it is reform or nonreform. The instruments are highly significant with a p-value of zero, both overall and for the two subsamples of higher and lower father's education. For those with unskilled fathers the point estimate is almost the same (column 5). However for those with skilled fathers the IV estimator is too imprecise to say much about it, although it is still negative as in all other cases. ${ }^{21}$ Thus there is no strong evidence that mobility is a source of bias for these results.

\section{Conclusion}

The reform of the Swedish education system had important effects on the earnings and the educational attainment of individuals. We establish a large increase in the share of student reaching the new compulsory level for the group with unskilled fathers and low ability. More interestingly, the reform led to an increase in schooling beyond the new compulsory level for individuals with higher ability and unskilled fathers. This may have helped increase intergenerational mobility by improving access beyond the new compulsory level. We also find that labour market earnings increased significantly for individuals with unskilled fathers; however there are also indications that earnings fell for individuals with higher skilled fathers, indicating that the abolition of selection may have reduced the quality of education obtained by this group. Nevertheless, the reform improved on average both the educational attainment and the earnings of a large part of the population.

\footnotetext{
${ }^{21}$ Because of the combination of the limited mobility and in the inability to classify a substantial number of individuals to reform/non-reform status using the municipality of birth.
} 


\section{Appendix: Descriptive Statistics}

\begin{tabular}{|c|c|c|c|c|}
\hline \multicolumn{5}{|c|}{ Descriptive statistics $^{a}$} \\
\hline \multirow[t]{2}{*}{ Variable } & \multicolumn{2}{|c|}{1948 Cohort } & \multicolumn{2}{|c|}{1953 Cohort } \\
\hline & Reform & Non-reform & Reform & Non-reform \\
\hline Reform assignment, \% & \multicolumn{2}{|c|}{34.2} & \multicolumn{2}{|r|}{80.6} \\
\hline Females, \% & 49.8 & 48.7 & 49.6 & 49.6 \\
\hline \multirow[t]{2}{*}{ Spatial IQ ${ }^{b}$} & 21.53 & 20.81 & 22.15 & 21.10 \\
\hline & $(7.29)$ & $(7.21)$ & $(7.35)$ & $(7.31)$ \\
\hline \multirow[t]{2}{*}{ Verbal IQ ${ }^{b}$} & 22.57 & 22.18 & 23.94 & 22.80 \\
\hline & $(6.96)$ & $(7.04)$ & $(6.70)$ & $(6.83)$ \\
\hline \multirow[t]{2}{*}{ Mathematical IQ ${ }^{b}$} & 19.43 & 19.28 & 20.43 & 19.20 \\
\hline & $(7.92)$ & $(7.98)$ & $(8.04)$ & $(8.01)$ \\
\hline Father's education more than compulsory, $\%$ & 16.8 & 13.6 & 20.9 & 14.6 \\
\hline \multirow[t]{2}{*}{ Years of schooling } & 11.81 & 11.15 & 11.60 & 10.84 \\
\hline & $(2.72)$ & $(3.07)$ & $(2.50)$ & $(2.73)$ \\
\hline less than 9 years of schooling, $\%$ & 4.0 & 22.1 & 1.73 & 18.9 \\
\hline 9 years of schooling, $\%$ & 22.3 & 10.3 & 30.0 & 20.5 \\
\hline More than 9 years of schooling, $\%$ & 73.7 & 67.6 & 68.3 & 60.6 \\
\hline Sample size, cross-section & 3,867 & 7,417 & 7,587 & 1,841 \\
\hline \multirow[t]{2}{*}{ Log labor earnings } & 7.28 & 7.24 & 7.19 & 7.11 \\
\hline & $(0.58)$ & $(0.60)$ & $(0.60)$ & $(0.61)$ \\
\hline Sample size, labor earnings & 40,121 & 76,571 & 79,431 & 18,581 \\
\hline
\end{tabular}

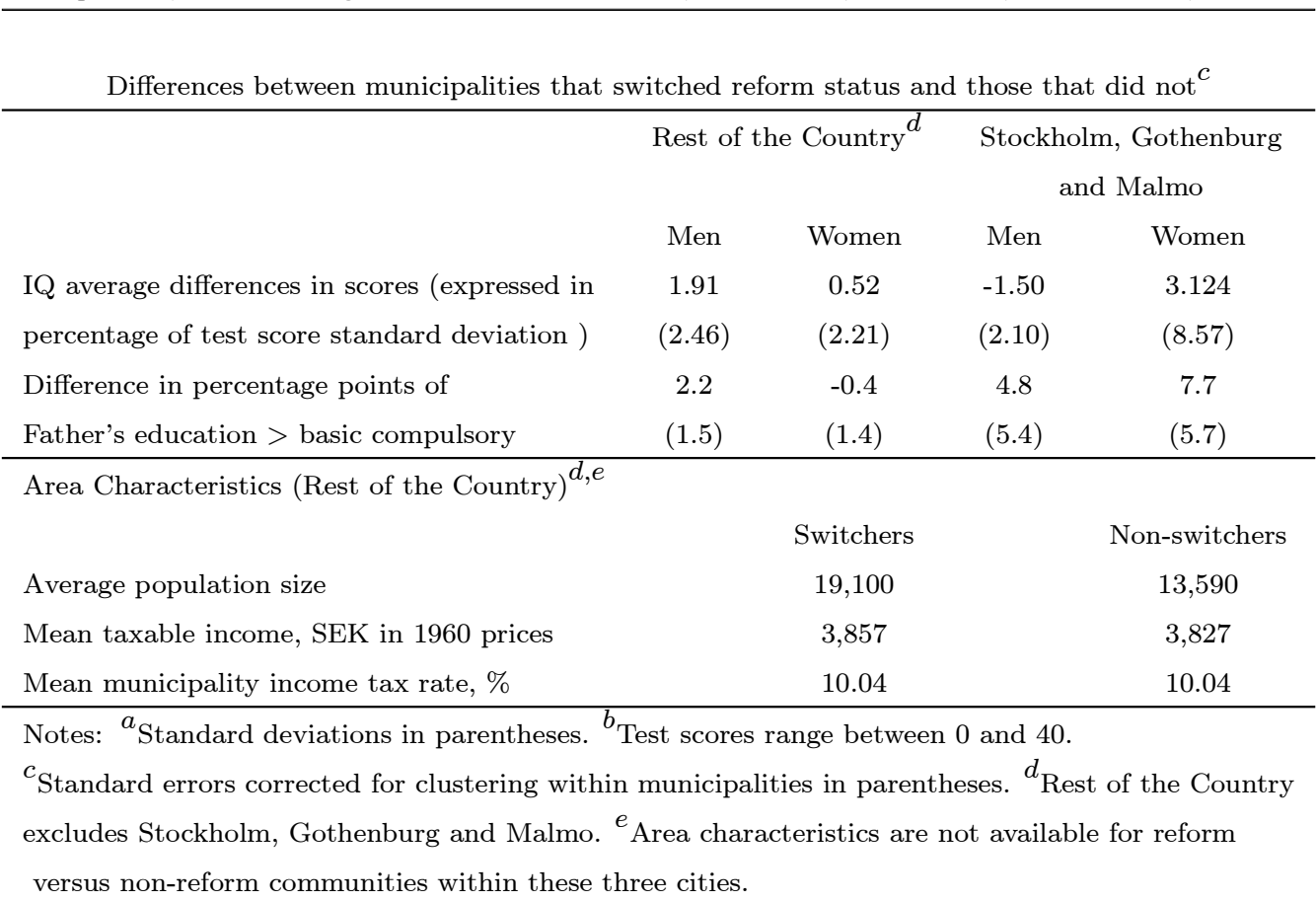

Table 1: Descriptive statistics and difference in the characteristics of individuals living in municipalities that switched into the reform for the 1953 cohort to those who lived in municipalities that did not change status for the two cohorts. 


\section{References}

1. Angrist, J. D. and A. B. Krueger (1991) "Does Compulsory Schooling Attendance Affect Schooling and Earnings?", Quarterly Journal of Economics 106, 970-1014.

2. Ashenfelter, O. (1978) "Estimating the Effect of Training Programs on Earnings", Review of Economics and Statistics 60, 47-57.

3. Card, D. (1999) "The Causal Effect of Education on Earnings", in O. Ashenfelter and D. Card, eds., Handbook of Labor Economics vol 3A. Amsterdam: North-Holland.

4. Card, D. (2001) "Estimating the Return to Schooling: Progress on Some Persistent Econometric Problems", Econometrica 69, 1127-1160.

5. Carneiro, P and J. J. Heckman (2003) "Human Capital Policy", Alvin Hansen Lecture 2002, University of Chicago mimeo.

6. Dearden, L., J. Ferri and C. Meghir (2002) "The Effect of School Quality on Educational Attainment and Wages" The Review of Economics and Statistics, 84, 1-20.

7. Försöksverksamhet med nioårig skolplikt (1959) National School Board, report 52, Stockholm.

8. Harmon, C. and I. Walker (1995) "Estimates of the Economic Return to Schooling for the United Kingdom", The American Economic Review 85, 1278-1286.

9. Härnqvist, K. and A. Svensson (1973) "A Swedish Data Bank for Studies of Educational Development", Sociological Microjournal 7, 35-42.

10. Heckman, J., (2000) "Policies to Foster Human Capital", Research in Economics 54, 3-56.

11. Heckman J.J. and R. Robb (1985) "Alternative Methods for valuating the Impact of Interventions" in Longitudinal Analysis of Labor Market Data, J.J. Heckman and B.. Singer (eds.), New York, NY:Wiley. 
12. Krueger, A. B. (2002) "Inequality, Too Much of a Good Thing", Working Paper \#466 Princeton University, Industrial Relations Section.

13. Lang, K. and D. Kropp (1986) "Human Capital versus Sorting: The Effects of Compulsory Attendance Laws", Quarterly Journal of Economics 101, 609624.

14. Leschinsky, A. and K. U. Mayer, eds. (1990) "The Comprehensive School Experiment Revisited: Evidence from Western Europe". Frankfurt am Main: Verlag Peter Lang.

15. Margo, R. A. and T. A. Finegan (1996) "Compulsory Schooling Legislation and School Attendance in Turn-of-the-Century America: A 'Natural Experiment' Approach", Economics Letters 53, 103-110.

16. Marklund, S. (1981) "Skolsverige 1950-1975: Försöksversamhet" Stockholm: Liber Utbildningsförlaget.

17. Meghir, C. and M. Palme (2003) "Ability, parental background and educational policy: empirical evidence from a social experiment" IFS working paper W03/05.

18. Moulton B. (1986) "Random Group Effects and the Precision of Regression Estimates," Journal of Econometrics 32, 385-397.

19. Paulston, R. (1968) "Educational Change in Sweden", Teachers College, Columbia University, New York.

20. Westerlund, O. (1994) "Economic Influences of Migration in Sweden", Ph. D. thesis Department of Economics, University of Umeå. 